\title{
Regional Development and Labor Turnover: More on the Frostbelt/Sunbelt Controversy
}

\author{
Robert Premus* and Rudy Fichtenbaum
}

\section{INTRODUCTION}

Much has been written about plant closings in the frostbelt states and the economic expansion of the sunbelt. Attempts to explain different development patterns are contradictory because assumptions made about the mobility of labor and capital permit competing theories to develop. Empirical studies that support the various views have emphasized the determinants of interregional migration and capital flows, but the implications of the alternative development theories for labor market turnover behavior (quits and layoffs) have not been tested.

The purpose of this paper is to rectify this deficiency in the regional economic development literature. A cross-section model of interindustry labor turnover behavior is developed and tested using data on the manufacturing sector in 1976. A surprising result of the study is the lack of evidence that workers are quitting their jobs in the frostbelt to move to the sunbelt. Moreover, the study found no evidence that layoff rates are significantly higher in the frostbelt, as would be expected if businesses in that region are closing their plants and moving to the sunbelt.

The study proceeds with a brief introduction in Section I. Section II discusses the competing theories of regional economic development and the implication of each theory for labor market turnover behavior. Section III presents the models of interindustry quit and layoff behavior that are used to test the labor market implications of the competing theories. The test results are presented in Section IV. Finally, a summary and conclusions are presented in Section V.

\section{COMPETING THEORIES OF REGIONAL DEVELOPMENT}

A "chicken or egg" controversy has emerged in the regional economic development literature. Do people migrate to regions experiencing economic expansion in pursuit of jobs or do population movements pre-

\footnotetext{
* Department of Economics, Wright State University. The authors are indebted to two anonymous referees of the journal for their helpful comments. Also, Barton Wechsler, Chairman, Department of Economics, Wright State University, is to be thanked for his insightful comments. Of course, the authors assume full responsibility for any errors that may appear in the paper.
} 
ceed job expansion? Some analysts (e.g., Borts and Stein, 1964) argue that population migration preceeds regional economic development (i.e., jobs follow people). Migrants are viewed as selecting a location independently of employment opportunities, resulting in population expansion in amenity rich regions (states). The region's labor supply function shifts to the right as population grows, resulting in a temporarily depressed wage rate. Lower factor costs, in turn, attract private and public investment leading to job expansion. In the long run, regional demand for labor is viewed as perfectly elastic at the initial wage rate.

Other analysts argue that people primarily follow jobs. The migration literature is replete with studies that have found changes in income and employment opportunities to be significant determinants of interregional and interstate migration flows (Greenwood, 1975). This people-followjobs approach implies that regional change in comparative advantage (e.g., energy rich states such as Texas, Louisiana and Alabama provide more attractive investment opportunities because of rising energy costs) results in variations in capital flows among the regions and states. A shift in capital investment expenditures leads to plant closings in the regions experiencing a decline in their comparative advantage and to plant additions and expansions in regions experiencing an improvement in comparative advantage. Population flows, in turn, will be diverted to the expanding regions as workers migrate in pursuit of jobs.

A third view of the regional economic development process has emerged in the economics literature (Thompson, 1975, and Allman and Birch, 1975). This approach (hereafter labeled the incubator approach) primarily views regional development as resulting from the difference between the formation of new firms (births) and business failures (deaths). Regional growth disparities, according to this view, occur primarily as a result of the interregional differentials in the factors that influence business formation rates, and not as a result of the migration of existing businesses. Capital investment in place is viewed as relatively immobile. Thus, the formation of new businesses and the expansion of existing ones provides the impetus for growth in the sunbelt; whereas, a decline in business starts and the reluctance of existing businesses to expand is viewed as the primary cause of economic stagnation in the frostbelt. In general, plant closing and business migration account for very little of the growth disparity between the sunbelt and frostbelt according to this view.

Each of the competing theories has testable implications for labor turnover behavior in the lagging regions. The people-follow-jobs approach suggests that workers in the frostbelt are involuntarily separating from their current jobs as a result of plant closings and moving to the sunbelt. Thus, industries with a large concentration of jobs in the frostbelt should experience a higher rate of involuntary separations (layoffs) than industries that are geographically dispersed. Worker quit behavior is expected to be affected as well. In particular, this view hypothesizes that workers in the declining states will quit their current employment-in anticipation of future layoffs and inadequate wage increases-and migrate to the sunbelt regions. Thus, if the people-follow-jobs approach is a valid 
explanation of regional development patterns, both layoffs and quit rates should be higher in industries more geographically concentrated in the frostbelt, ceteris paribus.

The jobs-follow-people approach suggests that quit rates in the frostbelt should reflect workers' preferences for amenities in the sunbelt. Thus, industries with a high concentration of jobs in the frostbelt should experience, other things equal, a higher quit rate than industries geographically concentrated in other regions. Also, business-initiated layoffs in the frostbelt would be higher because as people leave the region the demand for goods and services declines. Thus, if this theory has empirical validity, quit rates and layoff rates should be higher in industries that are geographically concentrated in the frostbelt.

The incubator hypothesis also has implications for labor turnover. Regions suffering from economic decline due to a low business formation rate are expected to experience increasing competition among workers for the available jobs. Search theory suggests that voluntary turnover depends on the availability of alternative economic opportunities as well as the cost of obtaining information about them (Lippman and McCall, 1977). To the extent that the incubator hypothesis is valid, the relative decline of economic opportunities in the frostbelt, coupled with imperfect worker knowledge of alternatives, is expected to reduce worker quit rates in industries that are geographically concentrated in the frostbelt. Also, plant layoffs are expected to be unaffected by geographical concentration since, according to the incubator hypothesis, plant closings are not the primary cause of economic stagnation. However, a lower layoff rate would also support the incubator hypothesis since it would imply that the relative decline of the frostbelt is not due to a loss of comparative advantage for existing industries.

\section{THE MODEL}

A two equation model to test the implications of the alternative regional growth theories for labor turnover is developed in this section. The model representing worker quit behavior for industries is presented in equation (1) as follows:

$$
\mathrm{X}_{1}=\mathrm{f}\left(\mathrm{X}_{3}, \mathrm{X}_{4}, \mathrm{X}_{5}, \mathrm{X}_{6}, \mathrm{X}_{7}, \mathrm{X}_{8}\right)
$$

where $\mathrm{X}_{1}=$ quits per 100 employees in the ith industry,

$\mathrm{X}_{3}=$ percent of ith industry employment in the frostbelt region, ${ }^{1}$

$\mathrm{X}_{4}=$ average hourly earnings per employee in the ith industry,

$\mathrm{X}_{5}=$ the number of industrial injuries and illness per 100 workers in the ith industry, 


$$
\begin{aligned}
\mathrm{X}_{6}= & \begin{array}{l}
\text { percent of workers in the ith industry that } \\
\text { belong to a union, }
\end{array} \\
\mathrm{X}_{7}= & \begin{array}{l}
\text { percent of establishments in the ith industry } \\
\text { with } 500 \text { or more employees, and }
\end{array} \\
\mathrm{X}_{8}= & \begin{array}{l}
\text { the ith industry accession rate per } 100 \\
\text { employees (recalls and new hires) lagged } \\
\text { one year. }
\end{array}
\end{aligned}
$$

The coefficient relating $\mathrm{X}_{3}$ and $\mathrm{X}_{1}$ should be positive if jobs follow people. A positive coefficient would indicate that workers in industries concentrated in the frostbelt have higher quit rates. Higher quit rates would indicate that workers in the frostbelt are quitting their jobs and moving to the sunbelt for a more favorable climate and other amenities. To a lesser degree it would also be consistent with the people-follow-jobs view that plant closings in the frostbelt are inducing workers to migrate to the sunbelt for economic security and economic opportunities. Conversely, a negative coefficient would support the incubator hypothesis since it would indicate that workers are reluctant to quit their jobs in the frostbelt because they are experiencing increasing competition for available jobs. Thus, the coefficient for $\mathrm{X}_{3}$ is considered a crucial test of the alternative theories of regional development.

The remaining independent variables in equation (1) are introduced to account for the other factors that influence interindustry quit rates. Firms that invest in human capital are expected to offer higher wages to retain their workforce. Thus, quit rates $\left(\mathrm{X}_{1}\right)$ and industry wage rates $\left(\mathrm{X}_{4}\right)$ are expected to be negatively related. Studies by Oi (1962), Pencavel (1972), Burton and Parker (1969), Stoikov and Raimon (1960), and Parsons (1972) support this hypothesis.

The probability of injury or illness on the job $\left(\mathrm{X}_{5}\right)$ is another variable that is expected to affect the worker-quit behavior. Viscusi (1969) has shown that work hazards have a positive effect on industry quit rates. Following Viscusi, we hypothesize a positive relationship between the incidents of industrial injuries and illnesses $\left(\mathrm{X}_{5}\right)$ and interindustry quit rates.

The presence of a union also affects worker-quit behavior. Studies by Stoikov and Raimon (1968) and Pencavel (1972) have found an inverse relationship between the percent of an industry's labor force belonging to a union $\left(\mathrm{X}_{6}\right)$ and worker-quit rates $\left(\mathrm{X}_{1}\right)$. Presumably, unions confer benefits on workers by giving them recourse to arbitration and negotiation to resolve issues and conflicts. Thus, a negative coefficient for variable $\mathrm{X}_{6}$ in equation (1) is expected.

Establishment size is also expected to influence worker-quit behavior, although the expected sign of the coefficient on $\mathrm{X}_{7}$ is indeterminant.

\footnotetext{
${ }^{1}$ The states included in the frostbelt region as defined in this study are as follows: Michigan, Indiana, Illinois, Ohio, Pennsylvania, New York, New Hampshire, Rhode Island, Massachusetts, Connecticut, Maine, Vermont and New Jersey. These states roughly constitute what Thompson (1975) called the "American Ruhr" since they represent the industrial heartland of the United States.
} 
Studies by Stoikov and Raimon (1968) and Burton and Parker (1969) found a negative relationship between quits and establishment size. They argue that large businesses provide greater opportunity for intrafirm mobility and they are less subject to the vagaries of the market place. Both of these factors are expected to reduce quit rates. However, the organizational behavior literature suggests that the bureaucratic control mechanisms of large organizations results in job dissatisfaction and higher turnover. This hypothesis is consistent with the findings of Porter and Steers (1973).

Finally, the accession rate lagged one year $\left(\mathrm{X}_{8}\right)$ is used as a proxy for the percent of an industry's labor force with brief job tenure. Following Pencaval (1972) and Stoikov and Raimon (1968), we hypothize a positive relationship between quit rates and the previous period accession rate. This hypothesis is based on the view that job search is an efficient mechanism for workers to acquire information about job characteristics and alternative employment opportunities. Thus, worker quitting can be expected to be higher in industries with a higher percentage of workers with brief tenure (Parsons 1977).

The layoff equation tested in this paper is presented as follows:

$$
\mathrm{X}_{2}=\mathrm{f}\left(\mathrm{X}_{3}, \mathrm{X}_{4}, \mathrm{X}_{9}, \mathrm{X}_{10}\right)
$$

where $\mathrm{X}_{2}=$ layoffs per 1,000 employers in the ith industry,

$$
\begin{aligned}
\mathrm{X}_{3}= & \begin{array}{l}
\text { percent of ith industry employment in the } \\
\text { frostbelt region, }
\end{array} \\
\mathrm{X}_{4}= & \begin{array}{l}
\text { average hourly earnings per employee in the ith } \\
\text { industry in } 1976,
\end{array} \\
\mathrm{X}_{9}= & \begin{array}{l}
\text { percent change in employment in the ith industry } \\
\text { from } 1971 \text { to } 1976, \text { and }
\end{array} \\
\mathrm{X}_{10}= & \begin{array}{l}
\text { the unemployment rate in the ith industry } \\
\text { relative to the unemployment rate for the } \\
\text { manufacturing sector in } 1976 \text {. }
\end{array}
\end{aligned}
$$

A coefficient not statistically different from zero, or a negative coefficient for $\mathrm{X}_{3}$ would support the incubator approach. As stated, it would indicate that the demise of the frostbelt economy is a result of a low business formation rate and not the relocation of existing businesses to the sunbelt. However, if people follow jobs, the coefficient for $\mathrm{X}_{3}$ should be positive. A high layoff rate in the industries geographically located in the frostbelt would indicate that the region is experiencing plant closures and relocations. If jobs follow people, a positive coefficient for $\mathrm{X}_{3}$ would also be expected since as people leave the region the demand for goods and services would be reduced resulting in layoffs. 
The average hourly wage rate $\left(\mathrm{X}_{4}\right)$ is expected to contribute positively to the layoff behavior of firms. High wages increase labor costs which can lead to layoffs (Bloch, 1979). Thus, industry wage rates and layoffs are expected to be positively associated.

Industry outlook is measured by variable $\mathrm{X}_{9}$, the percentage change in employment in the ith industry from 1971 to $1976 .{ }^{2}$ Industries experiencing secular decline (growth), other things equal, are expected to experience a high (low) layoff rate. Therefore, the coefficient on $\mathrm{X}_{9}$ is expected to be negative.

Finally, current economic conditions in the industry will influence layoff behavior. The unemployment rate is used in this study to reflect product demand conditions. Industries experiencing a decline in product demand are expected to initiate layoffs. An unemployment rate lower than the industry-wide norm would indicate strong product demand resulting in a low layoff rate. Thus, industry unemployment and layoff rates are expected to be positively related.

The sample used to test the competing theories consisted of 79 threedigit industries in the manufacturing sector in 1976. The data were obtained from several sources. Information on quits, layoffs, accessions, the percentage change in employment, and average hourly earnings were obtained from Employment and Earnings. Data on the proportion of an industry located in the frostbelt were available in the Census of Manufacturers. The number of occupational injuries and illnesses by industry was reported in Occupational Injuries and Illnesses in the U.S. The number of establishments with 500 or more employees was obtained from County Business Patterns. Data on unemployment by industry came from unpublished data collected by the Bureau of Labor Statistics. Finally, data on union membership were taken from Freeman and Medoff (1979).

IV. THE RESULTS

$$
\begin{gathered}
\mathrm{X}_{1}=3.548-0.77 \mathrm{X}_{3}-0.526 \mathrm{X}_{4}+0.0293 \mathrm{X}_{5}-0.0091 \mathrm{X}_{6} \\
(3.45) \quad(7.35) \quad(3.03) \quad(3.46) \\
+19.65 \mathrm{X}_{7}+\underset{(2.86) \quad 0.29 \mathrm{X}_{8}}{(3.46)} \\
\mathrm{R}^{2}=.89 \quad \mathrm{~F}=78.9 \quad \mathrm{~N}=61
\end{gathered}
$$

( $\mathrm{t}$ values are in parentheses)

${ }^{2}$ Both 1971 and 1976 are one year into a recovery from a recession. Taking employment changes from 1971-76 eliminates cyclical variation permitting isolation of long-term trends. 


$$
\begin{aligned}
& \mathrm{X}_{2}=0.575+0.00287 \mathrm{X}_{4}-1.277 \mathrm{X}_{9}+0.957 \mathrm{X}_{10} \\
& \begin{array}{lll}
(0.36) \quad(2.109) \quad(4.53)
\end{array} \\
& -0.651 \mathrm{X}_{3} \\
& \text { (1.83) } \\
& \begin{array}{lll}
\mathrm{R}^{2}=.30 & \mathrm{~N}=79 & \mathrm{R}=7.97
\end{array}
\end{aligned}
$$

( $\mathrm{t}$ values are in parentheses)

Overall, the regression results are quite encouraging. All of the regression coefficients, with the exception of the coefficients for $\mathrm{X}_{3}$ and $\mathrm{X}_{4}$ in equation (4), the layoff equation, are statistically significant at the 5 percent level. However, $\mathrm{X}_{3}$, a measure of regional concentration, is statistically significant at the 7 percent level. Equation (3) explains 89 percent of the interindustry variation in quit rates. Equation (4) explains only about 30 percent of interindustry variation in layoff rates, a relatively disappointing result.

Of particular interest is the coefficient for $\mathrm{X}_{3}$ in the quit equation. The coefficient for $\mathrm{X}_{3}$ is negative and statistically significant at the .05 level. This finding lends surrogate empirical support to the incubator hypothesis since it indicates that industries with a high degree of geographical concentration in the frostbelt exhibit lower quit rates. The coefficient for $\mathrm{X}_{3}(-0.651)$ in the layoff equation is also negative and statistically significant at the .07 level, lending additional support to the incubator hypothesis. Apparently, the relative decline of the frostbelt is not due to worker disenchantment with employment and environmental conditions or plant layoffs. Instead, the results support the view that economic stagnation in the frostbelt region is due to the inability of the region to stimulate business starts and expand existing businesses at a rate sufficient to absorb the growing labor force.

The other results of our study are interesting as well. In the quit equation, the estimated coefficients on wages $\left(\mathrm{X}_{4}\right)$, injury and illness rates $\left(\mathrm{X}_{5}\right)$, unions $\left(\mathrm{X}_{6}\right)$, and accessions lagged on year $\left(\mathrm{X}_{8}\right)$ all have the expected signs and they are significant at the 5 percent level. These findings are consistent with the studies by Oi, Pencavel, Burton and Parker, Stoikov and Raimon, Parsons, and Vicuisi cited previously. Establishment size $\left(\mathrm{X}_{7}\right)$ was found to have a positive and significant effect on quit rates. This finding contradicts Stoikov and Raimon (1958) and Burton and Parker (1969), but supports Porter and Steers (1973).

In the layoff equation, the wage variable $\left(\mathrm{X}_{4}\right)$ is positive but not statistically significant. Thus, it appears that high wages cannot be cited as a reason for layoffs. In addition, the coefficient for the unemployment rate $\left(\mathrm{X}_{10}\right)$ is positive and statistically significant, indicating that weak (strong) demand in the product market results in an increase (decrease) in layoffs. Finally, the coefficient for the percentage change in employment from 1971 to $1976\left(\mathrm{X}_{9}\right)$ is negative and significant at the 5 percent level. This 
variable acts as a proxy for industry outlook, indicating that as the percentage change in employment decreases (increases), other things equal, layoff rates increase (decrease).

\section{SUMMARY AND CONCLUSIONS}

This study focused on one aspect of the labor market implications of various competing theories of regional development. Specifically, labor turnover behavior in manufacturing industries concentrated in the frostbelt was examined. Both voluntary separations (quits) and involuntary separations (layoffs) were found to be lower in the frostbelt. In particular, quit rates and layoff rates were found to a declining function of the percent of an industry's employment in the frostbelt. This finding is consistent with the incubator hypothesis which suggests that the decline of older industrial states is attributable to their inability to stimulate business starts and expand existing industries. Allman and Birch (1975), Thompson (1975) and Harrison (1977) arrived at a similar conclusion, although unlike the present study they did not examine the relationship between regional development and labor turnover. In general, while this study does not resolve the controversy concerning competing theories of regional development, it does provide an alternative framework for testing the empirical implications of the regional development theories.

\section{REFERENCES}

Allman, P. A., and Birch, D. L., Components of Employment Change for States by Industry Group, 1970-72, Harvard University Massachusetts Institute of Technology Joint Center for Urban Studies. Working Paper Number 51, Cambridge, Massachusetts, September 1975.

Bloch, Farrel, "Labor Turnover in U.S. Manufacturing Industries," Journal of Human Resources 14:2 (Spring 1979): 236-45.

Borts, C. H., and Stein, J. L., Economic Growth in a Free Market, New York: Columbia University Press, 1964.

Burton, John J., and Parker, John E., "Interindustry Variations in Voluntary Labor Mobility," Industrial and Labor Relations Review 22:2 (January 1969): 199216.

Freeman, Richard B., and Medoff, James L., "New Estimates of Private Sector Unionism in the United States," Industrial and Labor Relation Review, 32:2 (January 1979): 143-74.

Greenwood, Michael J., "Research on Internal Migration in the United States: A Survey," Journal of Economic Literature, 13:2 (June 1975): 91-112.

Harrison, Benett, and Hill, Edward, "The Changing Structure of Jobs in Older and Younger Cities," presented to the Conference on Central City Economic Development, State University of New York at Binghamton, Center for Social Analysis, October 1977.

Lippman, Steven, and McCall, John, "The Economics of Job Search: A Survey," Economic Inquiry 14:2 (June 1976): 155-89.

Oi, Walter, "Labor as a Quasi-Fixed Factor," Journal of Political Economy, 70:6 (December 1962): 538-55.
Parsons, D. O., "Models of Labor Market Turnover: A Theoretical and Empirical Survey," Research in Labor Economics, Vol. 1 (ed.) Ronald Elvrenberg (Greenwich: JAI Press, 1977): 185-223.

, "Specific Human Capital: An Application to Quit Rates and Layoff Rates," Journal of Political Economy 80:4 (July/August 1972): 1120-43.

Pencavel, John J., "Wages, Specific Training and Labor Turnover in U.S. Manufacturing Industries," International Economic Review 13:1 (February 1972): 53-64.

Porter, L. W., and Steers, R. M., "Organizational, Work and Personal Factors in Employee Turnover and Absenteeism," Psychological Bulletin 80: (1973): 151-76.

Stoikov, V., and Raimon, R. L., "Determinants of Differences in the Quit Rate Among Industries," American Economic Review 58:5 (December 1968): 1283-98.

Thompson, Wilber, "Economic Process and Employment Patterns in Declining Metropolitan Areas," in Post Industrial America: Metropolitan Decline and Interregional Job Shifts, by George Sternlieb and James W. Huges (eds.), The Center for Urban Policy Research, Rutgers, New Brunswick, New Jersey, 1975, 187-96.

U.S. Department of Commerce, Bureau of the Census, County Business Patterns, 1976.

, Census of Manufacturers, 1976.

U.S. Department of Labor, Bureau of Labor Statistics, Employment and Earnings, March 1977.

, Bureau of Labor Statistics, Occupational Injuries and Illnesses in the U.S. by Industry, 1976, 1978.

Viscusi, Kip W., "Job Hazards and Worker Quit Rates: An Analysis of Adaptive Worker Behavior," International Economic Review 20:1 (February 1979): 29-58. 